\title{
Trade Policy in a Ricardian Model with a Continuum of Goods under Nonhomothetic Preferences
}

\author{
Joachim Stibora* and Albert de Vaal $^{\dagger}$
}

\begin{abstract}
We develop a Ricardian trade model with a continuum of goods that are ordered according to priority in consumption. Goods at the lower end of the spectrum are consumed by all households and when income increases households add higher-ranked goods to their consumption baskets. We apply this framework to address the issue of trade liberalization between a poor and rich country. The poor (rich) country has comparative advantage in the production of lower (higher) ranked goods. We find that the effects of trade liberalization on the terms of trade, specialization patterns and consumer welfare might differ fundamentally from the results predicted by trade models with homothetic preferences. Additionally, assuming nondegenerated income distributions, we show that the effects of trade liberalization on the relative income position of poor households depends on how tariff revenues are redistributed. It appears that the redistribution of tariff revenue from rich to poor households increases the burden of trade liberalization for poor households.
\end{abstract}

Keywords: Ricardian trade model; asymmetric demand complementarities; trade liberalization; income distribution

\section{JEL classification: F1}

${ }^{*}$ Faculty of Human Sciences, School of Economics, Kingston University, Kingston upon Thames, KT1 2EE; e-mail: j.stibora@kingston.ac.uk. Much of the writing was done while a fellow at the Nijmegen School of Management of the University of Nijmegen, The Netherlands, whose hospitality is greatly acknowledged. $\dagger$ Nijmegen School of Management, University of Nijmegen, The Netherlands. 


\section{Introduction}

In November 2001, a new round of multilateral trade talks, the so-called Doha Development Agenda, has been launched under the auspice of the World Trade Organization. Among the issues to be discussed are better access of poor countries to cheap generic drugs, the cuts of tariffs on industrial goods, and freer trade in agricultural products. Especially the latter has made politicians and negotiators of the developed countries to dub the current trade negotiations as the 'development round'. Due to the comparative advantage developing countries allegedly have in these industries, better access to the heavily distorted agricultural markets of developed countries is believed to be extremely beneficial for many developing countries in the world. This is what standard trade theory suggests and which has been empirically substantiated by the many studies that emerged in the wake of the launch of the Doha round talks.

This insight, however, is typically based on models where preferences are identical and homothetic, that is, where all goods have the same unitary income elasticities and where poor and rich households consume the available goods in the same proportion. This renders the income distribution irrelevant for explaining trade and the consequences of trade liberalization. In such models, trade is solely explained by differences in production conditions between countries and is not related to income difference across countries, nor to income differences within countries. For trade between developed and developing countries, this might be considered an heroic assumption. For instance, though supply conditions are certainly relevant for explaining trade between developed and developing countries, see e.g. Dosi et al. (1988), there is also empirical evidence that trade flows are generated by differences in per capita income across countries, e.g. Hunter and Markusen (1988) and Hunter (1991). The lower is the income level the more likely it is that the poorest households are isolated from the broader economy. This might imply that lower trade taxes do not get passed through to those households, simply because it is not something they consume yet. Consequently, the welfare of poor households might be affected more by increasing household incomes per se, which allows them to expand consumption baskets, than by re- 
ducing prices of goods that they did not consume in the first place. Standard trade models based on homothetic preferences are not suitable to address these issues, even though they seem highly relevant in assessing the consequences of better market access for developing countries.

In this paper we therefore abandon the assumption of homothetic preferences and look at the consequences of trade liberalization when preferences are nonhomothetic. To this end we use the Ricardian trade model developed by Matsuyama (2000), which builds on the well-known Dornbusch, Fischer and Samuelson (1977) framework, and extend it to include trade taxes. The production side is characterized by a continuum of goods which offers great analytical convenience. As in Matsuyama, but contrary to Dornbusch et al., commodities are ordered in terms of desirability and consumers are satiated after the consumption of one unit. Goods at the lower end of the spectrum are consumed by all households. When household income increases this takes the form of increased consumption of higherindexed goods, and not of increased consumption of the same goods. Indeed, this is the manifestation of nonhomothetic preferences, as it can be seen as a stylized representation of goods having different income elasticities. To apply the model to trade liberalization between developed and developing countries, we assume that the world consists of two countries: a poor, developing Home country and a rich, developed Foreign country. The low-income country has a comparative advantage in the production of the lower range of goods and specializes in goods with low income elasticity of demand. Foreign, on the other hand, has a comparative advantage in the production of the higher-spectrum of goods and hence is specialized in the commodities with high income elasticity of demand.

The inclusion of nonhomothetic preferences leads to three important results. First, trade liberalization does not necessarily lead to a deterioration of the terms of trade of the country that initiates the liberalization, as would be the outcome in standard models of trade. Consequently, the welfare of the incipient country may increase due to a terms of trade effect. The general inference is that a country gains from a unilateral tariff reduction when its factor terms of trade improves, regardless which country lowers the tariffs. When the terms of trade deteriorate, a unilateral tariff reduction is detrimental for a country, 
unless it is the incipient country. Second, the inclusion of nonhomothetic preferences also implies that the redistribution of tariff revenues within countries does affect aggregate variables since it influences a country's income distribution. As such, trade liberalization might affect the efficacy of governmental income redistribution policies. As our results indicate, in the presence of nonhomothetic preferences, the effects of trade liberalization become less positive for the poor in society, and might even become negative, when a government pursues an income redistribution policy in favour of the poor. Third, our framework provides an explanation for new industries to appear in the rich country due to trade liberalization, while some of its older industries move to the developing country. These effects can be seen as the standard gains of (further) specialization, but at the same time indicate the existence of product cycles. When preferences are nonhomothetic it appears that the birth of new industries is primarily driven by the higher purchasing power of rich households in the rich country. This implies that the more pro poor the income redistribution policy of a government is, the more effective trade liberalization is in spurring the birth of new industries.

This paper is also closely related to Wilson (1980) who generalizes the Dornbusch et al. model to many countries and some nonhomothetic preferences. He shows that many of the comparative static results derived by Dornbusch et al. carry over provided that goods are gross substitutes and differences in income elasticities are not too large. However, it is not clear how his comparative static results change when there are significant differences in income elasticity and goods are not gross substitutes due to the loss of tractability of his model. In contrast to Wilson and in the spirit of Matsuyama, we provide a tractable model and analyze the effects of trade policy when income elasticities differ significantly across countries.

The structure of the paper is as follows. Section 2 discusses the model and derives the initial, tariff distorted equilibrium. Section 3 starts the discussion on the effects of various trade policies when preferences are nonhomothetic, but disregards income distribution effects by assuming homogeneous population. The purpose of this section is to illustrate the implications of asymmetric demand complementarities. Section 4 considers differences in 
income distribution and investigates the effect of trade liberalization under the assumption of various tariff revenue distribution schemes. Section 5 concludes.

\section{The model}

There is a continuum of competitive industries, indexed by $z \in[0, \infty)$, each producing a homogenous good also indexed by $z$. There is one factor of production, labor, which is supplied in fixed quantity and denoted by $L$ and $L^{*}$ for the Home country and the Foreign country, respectively. As usual, an asterisk denotes the Foreign country. For good $z$, let $a(z)$ be the unit labor requirement in the home country and $a^{*}(z)$ the unit labor requirement in the Foreign country. We define $a^{*}(z) / a(z)$ as the ratio of domestic to foreign labor productivity and follow standard practice and rank commodities in order of diminishing home comparative advantage:

$$
\frac{a^{*}(z)}{a(z)} \equiv A(z)
$$

The function $A(z)$ is assumed to be continuous and strictly decreasing in $z, A^{\prime}(z)<0$.

We start from a situation in which trade flows are distorted by tariffs. Let $\tau=1+t$ be one plus the ad valorem tariff imposed by Home when importing good $z$ from Foreign. And similarly for Foreign. All goods traded face a uniform tariff rate. Then, assuming perfect competition, prices will adjust and Home imports any commodity $z$ from Foreign for which

$$
w a(z) \geq \tau w^{*} a^{*}(z) \quad \text { or } \quad w \geq \tau A(z)
$$

when we choose the foreign wage rate as numéraire $\left(w^{*}=1\right)$, so that the home wage rate $w$ is also Home's factor terms of trade. Similarly, Foreign imports any commodity $z$ from Home for which

$$
A(z) \geq \tau^{*} w
$$

As is well known, cost barriers to importing lead to a range of commodities that are not traded. By imposing equalities in (2) and (3) we define borderline commodities. Thus $\widetilde{z}$ is the borderline between the home country's nontraded commodities and the foreign 
country's exports and $\widetilde{z}^{*}$ represents the borderline between the home country's exports and Foreign country's nontraded commodities:

$$
\begin{aligned}
& \widetilde{z}^{*}=A^{-1}\left(\tau^{*} w\right) \\
& \widetilde{z}=A^{-1}(w / \tau)
\end{aligned}
$$

which implies $\widetilde{z}^{*}<\widetilde{z}$, since $\tau, \tau^{*}>1$.

Since $A(z)$ is decreasing in $z,(2)$ and (3) imply that the home country produces all $z \in[0, \widetilde{z}]$ and the foreign country all $z \in\left[\widetilde{z}^{*}, \infty\right)$. Commodities $z \in\left[0, \widetilde{z}^{*}\right]$ are exclusively produced in Home and exported, since Home's inherent cost advantage in these goods is high enough to outweigh the trade taxes. At the same time, Foreign's cost advantage in $z \in[\widetilde{z}, \infty)$ is so high that those higher-indexed goods are exclusively produced there and exported. Goods $z \in\left(\widetilde{z}^{*}, \widetilde{z}\right)$ define an intermediate range of goods that both countries produce but do not trade. Productivity differences are not high enough to outweigh the trade taxes and engage in trade. Local prices are thus determined by

$$
\begin{aligned}
p(z) & =\min \left\{w a(z), \tau a^{*}(z)\right\} \\
p^{*}(z) & =\min \left\{a^{*}(z), \tau^{*} w a(z)\right\} .
\end{aligned}
$$

The equilibrium $\widetilde{z}^{*}$ and $\widetilde{z}$ are determined by the interaction of demand and technology. Regarding the demand side, suppose there are $N$ households in the home country and $N^{*}$ in the foreign country. We follow Matsuyama (2000) and assume that the income distribution is nondegenerated and brought about by differences in skills and reflected in differences in effective labor supply. Let $F(h)$ and $F^{*}\left(h^{*}\right)$ be the distribution of effective labor supply across households in the home country and the foreign country, respectively. The total labor supply thus equals $L=N \int_{0}^{\infty} h d F(h)$ in Home and $L^{*}=N^{*} \int_{0}^{\infty} h^{*} d F^{*}\left(h^{*}\right)$ in Foreign. Since $N$ and $N^{*}$ are fixed, both countries' labor supplies are fixed as well.

The consumption set of a household includes a continuum of $z \in[0, \infty)$. All households have identical preferences and maximize $V=\int_{0}^{\infty} b(z) x(z) d z$ subject to the budget constraint $\int_{0}^{\infty} p(z) x(z) d z \leq I$. In these expressions, $b(z)>0$ is the utility received of consuming good $z$ and $x(z)=\{0,1\}$ denotes the 'quantity' a household consumes. Thus, 
following Murphy, Shleifer, and Vishny (1989), we assume that units come in discrete units and that household's desire to consume good $z$ is satiated after the consumption of one unit. This has the strong implication that, in contrast to standard analysis, an increase in the utility is reflected in the consumption of an increased number of goods rather than in the consumption of higher quantities of a fixed number of goods. As such, wealthier households consume all the goods consumed by poor households, plus some. The order in which each household purchases goods is assumed to be the same as the order of goods due to comparative advantage. Hence, we assume that households purchase lower-indexed goods first and when income increases extend their consumption to higher-indexed goods, which indeed is a characterization of nonhomothetic preferences. This requires that the order of utility per unit price is strictly decreasing in $z$, that is, we assume

$$
\begin{aligned}
\frac{b(z)}{p(z)} & =\frac{b(z)}{\min \left\{w a(z), \tau a^{*}(z)\right\}} \\
\frac{b(z)}{p^{*}(z)} & =\frac{b(z)}{\min \left\{a^{*}(z), \tau^{*} w a(z)\right\}}
\end{aligned}
$$

is strictly decreasing in $z$ for given $w, \tau$, and $\tau^{*}$. In combination with our assumptions on relative factor productivity and the ranking of factor intensity, this implies that the home country has a comparative advantage in the production of lower-range goods for poorer households, whereas the Foreign country has a comparative advantage in the production of higher-range goods that are purchased by richer households.

Since each country levies tariffs on each others imports, a home household has two potential sources of income: wage income and revenues from trade taxes. We assume that the tariff revenues each household generates by its own, household-specific spending on imported goods, if any, are collected by the government and redistributed across all households in a lump-sum fashion. Denoting these tariff rebates by $T R$, the highest-indexed commodity a home household is able to consume, $u(h)$, is determined by the requirement that

$$
E[u(h)]=w h+T R .
$$


Equation (4) states that the utility level a household in the home country attains when consuming $u(h)$ is $V(h)=B(u(h))$ where $B(z) \equiv \int_{0}^{z} b(s) d s$. This shows that $V(h)$, the level of utility attained by a household, maps one-to-one into $u(h)$, the highest-indexed good it consumes. The latter can therefore be used as a measure of utility.

Similarly, Foreign produces high-indexed commodities and imports the lower-indexed goods from the home country paying a tariff inclusive price for every good $z$ imported. Denoting foreign tariff rebates by $T R^{*}$, the highest range good the foreign household consumes, $u^{*}\left(h^{*}\right)$, is given by:

$$
E\left[u^{*}\left(h^{*}\right)\right]=h^{*}+T R^{*}
$$

The utility the foreign household achieves is $V^{*}\left(h^{*}\right)=B\left(u^{*}\left(h^{*}\right)\right)$.

Tariff revenues in Home and Foreign are a function of expenditures and since tariff revenues are part of household income, total tariff revenues are a function of themselves. If importing, home households import only $z \in(\widetilde{z}, \infty)$ paying $(\tau-1) a^{*}(s)$ for each unit consumed multiplied by total demand. This generates total tariff revenues of

$$
T=(\tau-1) \int_{\widetilde{z}}^{\infty} a^{*}(z) Q(z) d z
$$

where $Q(z)$ denotes total home demand for good $z$ as specified by (9). Similarly, foreign households import only goods in $z \in\left[0, \widetilde{z}^{*}\right]$ paying $\tau w a(z)$ per unit imported. Hence,

$$
T^{*}=\left(\tau^{*}-1\right) \int_{0}^{\widetilde{z}^{*}} w a(z) Q^{*}(z) d z
$$

where $Q^{*}(z)$ denotes total foreign demand for good $z$ as specified by (9). After some algebra, this becomes

$$
\begin{aligned}
T & =(\tau-1) N \int_{0}^{\infty} \max \{w h+T R-E(\widetilde{z}), 0\} d F(h) \\
T^{*} & =\left(\tau^{*}-1\right) N^{*} \int_{0}^{\infty} \min \left\{h^{*}+T R^{*}, E\left(\widetilde{z}^{*}\right)\right\} d F^{*}\left(h^{*}\right) .
\end{aligned}
$$

We assume for now that governments distribute tax revenues equally across households, that is $T R=T / N$ and $T R^{*}=T^{*} / N^{*}$. 
We now turn to the labor markets and examine how the derived demand for labor depends upon the demand for final goods. We assume that households differ only with respect to their income. These differences in household income are obviously due to differences in $h$, but also depend on the redistributive policies of local governments.

Since the home country produces only goods in $[0, \widetilde{z}]$ of which $\left[0, \widetilde{z}^{*}\right]$ are exported, labor market equilibrium in Home requires that labor supply equals labor demand:

$$
N \int_{0}^{\infty} h d F(h)=\int_{0}^{\tilde{z}} a(z) Q(z) d z+\int_{0}^{\tilde{z}^{*}} a(z) Q^{*}(z) d z .
$$

The left hand side of (8) represents Home's labor supply as the 'adding up' of the effective labor supplies of individual households. The right hand side of (8) is the derived demand for Home's labor, i.e., specifying how the demand for labor depends upon the total demand for good $z$. Since good $z$ is purchased by households whose income is higher than $E(z)$, and no household buys more than one unit of any good, total demand for good $z$ consists of the sum of households in both countries whose income is higher than $E(z)$ :

$$
\begin{aligned}
& Q(z)=N[1-F(E(z)-T R) / w)] \\
& Q^{*}(z)=N^{*}\left[1-F\left(E(z)-T R^{*}\right)\right] .
\end{aligned}
$$

Labor market equilibrium for the home country can be derived by equating the total income earned in the economy to worldwide expenditures on home goods. This yields,

$$
\begin{aligned}
w L= & N \int_{0}^{\infty} \min \{w h+T R, E(\widetilde{z})\} d F(h) \\
& +N^{*} \int_{0}^{\infty} \min \left\{h^{*}+T R^{*}, E\left(\widetilde{z}^{*}\right)\right\} d F^{*}\left(h^{*}\right)
\end{aligned}
$$

where $E(\widetilde{z})=\int_{0}^{\widetilde{z}} p(s) d s=\int_{0}^{\tilde{z}} w a(s) d s$ and $E\left(\widetilde{z}^{*}\right)=\tau^{*} \int_{0}^{\widetilde{z}^{*}} w a(s) d s$. An individual household spends $\min \{w h+T R, E(\tilde{z})\}$ on home goods and a foreign household $\min \left\{h^{*}+\right.$ $\left.T R^{*}, E\left(\tilde{z}^{*}\right)\right\}$. Note that $T R$ is only positive if the income of (some of the) home households exceeds $E(\widetilde{z})$, otherwise $T R=0$. The tariff rebates for foreign households, in contrast, are always positive, since Foreign always imports the lower-indexed goods produced by Home.

The foreign country produces only goods in $\left[\widetilde{z}^{*}, \infty\right)$ of which $[\widetilde{z}, \infty)$ are possibly ex- 
ported. Foreign labor market equilibrium therefore requires

$$
N^{*} \int_{0}^{\infty} h^{*} d F^{*}\left(h^{*}\right)=\int_{\widetilde{z}^{*}}^{\infty} a^{*}(z) Q^{*}(z) d z+\int_{\widetilde{z}}^{\infty} a^{*}(z) Q(z) d z .
$$

with $Q(z)=N[1-F(E(z)-T R) / w)]$ and $Q^{*}(z)=N^{*}\left[1-F\left(E(z)-T R^{*}\right)\right]$.

Households will only buy the higher-indexed commodities produced by Foreign when their income exceeds $E(\widetilde{z})$. Consequently, the labor market equilibrium condition in Foreign can be rewritten as

$$
\begin{aligned}
L^{*}= & N \int_{0}^{\infty} \max \{w h+T R-E(\widetilde{z}), 0\} d F(h) \\
& +N^{*} \int_{0}^{\infty} \max \left\{h^{*}+T R^{*}-E\left(\widetilde{z}^{*}\right), 0\right\} d F^{*}\left(h^{*}\right) .
\end{aligned}
$$

A home household spends $\max \{w h+T R-E(\widetilde{z}), 0\}$ and a foreign household $\max \left\{h^{*}+T R^{*}-E\left(\widetilde{z}^{*}\right)\right.$ on foreign goods.

Since both economies are linked by trade, Walras' law implies that equations (10) and (12) are identical in the equilibrium they accomplish and can therefore be effectively substituted by the condition for balanced trade. Hence, goods market equilibrium worldwide is governed by

$$
\begin{aligned}
& N^{*} \int_{0}^{\infty} \min \left\{\frac{h^{*}+T R^{*}}{w}, \frac{E\left(\widetilde{z}^{*}\right)}{w}\right\} d F^{*}\left(h^{*}\right)= \\
& N \int_{0}^{\infty} \max \left\{h+\frac{T R}{w}-\frac{E(\widetilde{z})}{w}, 0\right\} d F(h) .
\end{aligned}
$$

The first row represents the value of the home country's exports which in equilibrium have to be equal to its value of imports. We will refer to this equation as the trade balance condition. The particular form it takes crucially depends on whether or not all households in Foreign are rich enough to afford the higher-ranged goods that Foreign produces. When some of the foreign households are so poor that they can only afford to consume goods produced in Home, the trade balance condition is a positively sloped function of $w$. A lower relative wage rate of home laborers then leads to an increase in the purchasing power of those poor foreign households which indirectly increases the demand for home labor. To restore equilibrium, Home has to reduce the range of goods it produces which calls for an increase in $w$. However, when the relative home wage is sufficiently low so that all 
foreign households can afford foreign products, the trade balance condition is vertical. Any wage rise in Home translates completely into higher spending on foreign goods by home households, which in equilibrium exactly matches the increase in Foreign's import value due to higher prices of home goods.

Equations (2), (3), (4), (5), and (13) define a system of equations jointly determining the equilibrium values of $\widetilde{z}, \widetilde{z}^{*}, w, u$, and $u^{*}$. In the next sections we will use the model to infer the consequences of trade policy when preferences are non-homothetic. At this point, it is instructive to compare the present model with the Dornbusch, Fischer \& Samuelson (1977) model (henceforth DFS model). DFS assume that all households have identical and homothetic preferences over a fixed range of commodities. This implies that each household spends a constant share of expenditure on the $i$ th commodity. As part of the equilibrium, a household spends one part of its income on goods produced in Home and the remaining part on goods produced in Foreign. As a consequence of homothetic preferences, a lower price of home goods is an incentive for all households to substitute the relative more expensive foreign goods for home goods. This is in stark contrast to our model. There a fall in the price of goods produced in Home generates a higher demand for foreign produced goods due to the presence of demand complementarities. The decline in the price of lower-indexed goods increases the real income of households, which only increases consumption of higherindexed goods. The demand complementarities are asymmetric however, so that if the price of higher-ranked goods falls, demand for lower-indexed goods does not increase.

A direct implication of this is that in the DFS model the trade balance condition is positively sloped (from the origin), whereas in our model the trade balance condition is only positively sloped above a certain level of $w$. Moreover, the assumption of homotheticity in the DFS model implies that redistribution policies within a country do not affect aggregate variables such as $\widetilde{z}, \widetilde{z}^{*}$, and $w$. In our model, as is apparent from (13), the distribution of income affects the endogenous variables as a result of the asymmetric demand complementarities. 


\section{Trade policy with homogeneous population}

To build intuition of the implications of asymmetric demand complementarities, this section neglects income distribution effects and assumes that households in each country are homogeneous and endowed with one unit of effective labor, i.e., $h=h^{*}=1$. Moreover, it only considers the case in which households in both countries are rich enough in equilibrium to consume goods produced in Foreign, implying that in both countries marginal income is spent in Foreign, that is, $w+T R>E(\tilde{z})$ and $1+T R^{*}>E\left(\tilde{z}^{*}\right)$. Consequently, the initial equilibrium will be on the vertical part of the trade balance condition.

Making use of the expressions for consumer expenditures (4) and (5), while substituting for tariff revenues, the balanced trade condition for homogeneous population becomes,

$$
N^{*} \tau^{*} \int_{0}^{\tilde{z}^{*}} a(s) d s=N \tau\left[1-\int_{0}^{\tilde{z}} a(s) d s\right]
$$

provided that

$$
w<\bar{w} \equiv\left[1+\frac{N^{*} \tau^{*}}{N \tau}\right]\left[1-\int_{\widetilde{z}^{*}}^{\tilde{z}} a(s) d s\right]^{-1}
$$

since we assume that foreign households are rich enough to consume some of the goods they produce themselves. The equilibrium condition reduces to the Matsuyama (2000) case when there are no tariff impediments (so that $\widetilde{z}^{*}=\widetilde{z}$ ). For positive tariffs, the relation between $\widetilde{z}^{*}$ and $\widetilde{z}$ is governed by (2) and (3). Since $A(z)$ is strictly decreasing in $z$, this implies that we can express $\widetilde{z}^{*}$ as a function of $\widetilde{z}$. Hence,

$$
\widetilde{z}^{*}=A^{-1}\left[\tau A(\widetilde{z}) \tau^{*}\right]
$$

Inserting this in (14) the balanced trade condition becomes a function of $\widetilde{z}$ only: ${ }^{1}$

$$
N^{*} \tau^{*} \int_{0}^{A^{-1}\left[\tau A(\tilde{z}) \tau^{*}\right]} a(s) d s=N \tau\left[1-\int_{0}^{\tilde{z}} a(s) d s\right] .
$$

This expression defines the equilibrium value of $\tilde{z}$ and is independent of $w$ as long as $w<\bar{w}^{2}$ This reflects the fact that, when the consumption baskets of home and foreign

\footnotetext{
${ }^{1}$ For a similar analysis see Obstfeld \& Rogoff (1999).

${ }^{2}$ Likewise, we could have expressed equation (16) as a function of $\widetilde{z}^{*}$ only, with obviously no consequences for the analysis whatsoever. Only when graphically illustrating trade policy effects, it will prove convenient to be able to switch among the two equivalent specifications of (16).
} 
households both include higher-indexed foreign goods, any change in $w$ only works through via its impact on $\tilde{z}$ and $\tilde{z}^{*}$. Demand complementarities also explain why direct expenditure effects of changes in $w$ are absent in (16). Any wage rise in Home translates completely into higher spending on foreign goods by home households, which in equilibrium exactly matches the increase in Foreign's import bill due to the higher prices for home goods.

The model's equilibrium is complete when we combine the equilibrium $\tilde{z}$ with (2), which yields the equilibrium value of $w$. Using the equilibrium value of $w$ in (3), we know $\widetilde{z}^{*}$. Figure 1 illustrates the initial tariff distorted equilibrium achieved. In the figure, the TB and $A(z) \tau$ schedules jointly determine equilibrium, while the $A(z) / \tau^{*}$ schedule is only used to read off the equilibrium $\widetilde{z}^{*}$ that results. Note that we have drawn equilibrium on the vertical stretch of the trade balance condition TB, which is in line with the condition above. For $w>\bar{w}$, however, the trade balance condition becomes positively sloped as it depends on $w$. Formally,

$$
\left[N^{*}\left(\tau^{*}-1\right)+N \tau\right] \int_{0}^{\tilde{z}^{*}} a(s) d s=N \tau\left[1-\int_{\tilde{z}^{*}}^{\tilde{z}} a(s) d s\right]-N^{*} / w .
$$

This is the case when only home households are rich enough to buy foreign goods, which we will however not consider here. In our analysis we will also assume that equilibrium remains on the vertical part of the TB schedule.

In the initial tariff ridden equilibrium, the highest-indexed good a household in Home and Foreign consumes and thereby the utility level she attains is obtained from combining (4) with (6) and (5) with (7):

$$
\begin{gathered}
\int_{\widetilde{z}}^{u} a^{*}(s) d s=w-\int_{0}^{\widetilde{z}} w a(s) d s \\
\int_{\widetilde{z}^{*}}^{u^{*}} a^{*}(s) d s=1-\int_{0}^{\tilde{z}^{*}} w a(s) d s .
\end{gathered}
$$

We follow Matsuyama (2000) and assume that Home has an absolute disadvantage in the production of all $z$, that is, $a^{*}(z)>a(z)$ for all $z$. This ensures that $w<1$ and that (17) and (18) satisfy $\widetilde{z}^{*}<\widetilde{z}<u<u^{*}$ making foreign households richer than home households in equilibrium. home households consume all the goods produced in home plus some 
foreign goods $(\widetilde{z}<u)$, while foreign households consume all the goods home households consume plus some $\left(u<u^{*}\right)$. When $1<w<\bar{w}$, however, Home is the richer country and $u^{*}<u .^{3}$ It follows from the combination of the assumption on $A(z), b(z) / p(z), b(z) / p^{*}(z)$ and $a^{*}(z)>a(z)$, that Home specializes in goods whose demand is characterized by low income elasticities while Foreign in goods with high demand elasticities.

\section{Unilateral and multilateral trade liberalization}

Consider first the case in which Home reduces uniformly its tariffs on higher-indexed imports from Foreign, that is $d \tau<0$ while keeping $\tau^{*}$ unchanged. For the supply side the decline in tariffs implies a loss in competitiveness and therefore Home will produce a lower range of goods. The demand effect is that lower import tariffs imply more demand for imported goods and the trade balance goes in deficit. Hence, at impact both effects imply a lower $\widetilde{z}$. By total differentiation of (2), (3), and (14) it appears that also the equilibrium effect of lowering Home's tariffs is a lower $\widetilde{z}$ :

$$
\frac{\widehat{\widetilde{z}}}{\widehat{\widehat{\tau}}}=\frac{1}{D}\left[\zeta\left(\widetilde{z}^{*}\right) N \tau \int_{\widetilde{z}}^{u} a^{*}(s) d s+N^{*} \tau^{*} w a\left(\widetilde{z}^{*}\right) \widetilde{z}^{*}\right]>0
$$

where $\zeta(z) \equiv\left[\hat{a}(z) / \hat{z}-a^{*}(z) / \hat{z}\right]=-\hat{A}(z) / \hat{z}>0$ measures the elasticity of Home's relative efficiency with respect to the borderline commodity $z=\tilde{z}, \tilde{z}^{*}$ and where $D=$ $\zeta\left(\widetilde{z}^{*}\right) N w \tau a(\widetilde{z}) \widetilde{z}+\zeta(\widetilde{z}) N^{*} w \tau^{*} a\left(\widetilde{z}^{*}\right) \widetilde{z}^{*}>0$. A caret over a variable indicates a proportional rate of change, for example $\widehat{\tau}=d \tau / \tau$. A unilateral reduction of Home's tariffs thus unambiguously lowers the range of goods Home produces. The higher-ranged non-traded goods of Home are 'lost' to Foreign and Home now imports these goods.

The direct consequence of the loss of home industries at impact is that, keeping wages fixed, the real income of home households increases. The range of goods Home loses to Foreign have become cheaper, which raises Home's real income. Note that the price decline of previously imported goods in Home does not affect real income, since the gain due to lower prices is exactly compensated by the decrease in income due to lower tariff rebates.

\footnotetext{
${ }^{3}$ This case implies either $\widetilde{z}^{*}<\widetilde{z}<u^{*}<u$ or $\widetilde{z}^{*}<u^{*} \leq \widetilde{z}<u$, which is however not relevant for the comparative static results.
} 
The asymmetry of demand complementarities imply that the real income gain in Home is spent on imports only. Next to switching consumption of previously non-traded goods to imported goods $(d \tilde{z}>0)$, home households thus also increase the range of goods consumed $(d u>0)$. For Foreign, there is no real income effect due to the lower $\tilde{z}$, since the tariff inclusive price in Foreign does not change.

But when $\tilde{z}$ changes, also other effects occur. This depends on the extent by which $\tilde{z}$ decreases though. We illustrate this in Figure 2, where the tariff shock is given by the leftward shift of the schedule $A(z) \tau$ and by the leftward shift of the trade balance condition. As the figure shows, the effects on $w$ and $\tilde{z}^{*}$ are ambiguous and depend on the relative change in industries due to the lower level of protection (the shift of $A(z) \tau$ ), compared to the relative change in $\tilde{z}$ that is required to retain balance of payments equilibrium (the shift of TB). In the figure this is indicated by depicting two different leftward shifts of the trade balance condition. The vertical intercept (a) denotes the case in which the percentage change in $\tau$ leads to a larger than percentage change in range of goods Home produces, so that the equilibrium wage in Home increases to $w_{A}$ and the range of goods exported declines to $\left[0, \widetilde{z}_{A}^{*}\right]$. The vertical intercept (b) depicts a case where the percentage change in $\tau$ leads to a lower than percentage change in range of goods Home produces and home wages fall to $w_{B}$, while the range of goods exported to Foreign expands $\left[0, \widetilde{z}_{B}^{*}\right]$. When the leftward shift of the balanced trade condition exactly matches the leftward shift of the $A(z) \tau$ schedule, no effects on $w$ and $\tilde{z}^{*}$ occur.

Formally, the effects on $w$ and $\tilde{z}^{*}$ are given by

$$
\begin{aligned}
& \frac{\widehat{w}}{\widehat{\tau}}=\frac{\zeta\left(\widetilde{z}^{*}\right)}{D}\left[N \tau w a(\widetilde{z}) \widetilde{z}-\zeta(\widetilde{z}) N \tau \int_{\widetilde{z}}^{u} a^{*}(s) d s\right] \\
& \frac{\widehat{\widetilde{z}}^{*}}{\widehat{\tau}}=-\frac{1}{D}\left[N \tau w a(\widetilde{z}) \widetilde{z}-\zeta(\widetilde{z}) N \tau \int_{\widetilde{z}}^{u} a^{*}(s) d s\right]
\end{aligned}
$$

so that $\hat{w} / \hat{\tau} \gtreqless 0$ and $\tilde{z}^{*} / \hat{\tau} \lesseqgtr 0$ if $w a(\widetilde{z}) \widetilde{z} / \int_{\widetilde{z}}^{u} a^{*}(s) d s \gtreqless \zeta(\widetilde{z})$. The right-hand-side of this condition gives the extent to which Home loses goods to Foreign due to diminished competitiveness. The value of this elasticity is between zero and infinity. When $\zeta(\widetilde{z})$ is close to zero, comparative advantage hardly changes when $z$ changes — the curve is flat - and 
a relative wage increase implies that many goods are lost to Foreign. The left-hand-side of the condition gives the import value of the outlays on the marginal commodity $\tilde{z}$, reflecting the income effect of lower tariffs. If this ratio is one, then everything home households 'save' by not longer buying domestic goods is spent on foreign goods. This reduces the relative demand for home labor and only when this is matched by an identical relative decline in home labor demand due to the loss in competitiveness, will the factor terms of trade remain intact. ${ }^{4}$ In Figure 2, this would result in a proportional shift of both curves so that $\hat{\tau}=\hat{z}^{5}$ When, however, due to lower protection the loss of industries is larger (smaller) than required to get trade balance equilibrium, Home's relative wage will have to go down (up) to adjust the number of industries upward (downward). ${ }^{6}$

Making the comparison with the DFS analysis, we note that also there a unilateral reduction of home tariffs reduces the range of goods Home produces. However, in the DFS analysis Home's relative wage rate unambiguous falls when $\tau$ declines. In their model, the induced fall in the price of home goods generates an income effect as discussed before and a substitution effect. Due to the assumption of homothetic preferences in the form of Cobb Douglas utility function, the substitution effect dominates the income effect so that the demand for home goods increases. Consequently, Home's factor terms of trade unambiguously deteriorate when it unilaterally reduces its tariff. In our model, however, also the slope of the $A(\widetilde{z}) / \tau$ curve matters. Since there is no restriction on the magnitude of $\zeta(\widetilde{z})$, the terms of trade can also improve for Home.

Let us also consider a unilateral reduction of foreign tariffs $\left(d \tau^{*}<0, d \tau=0\right)$. Lower foreign trade taxes means that Foreign is now able to obtain previously nontraded commodities at a lower price from Home through trade and consequently Foreign 'loses' some

\footnotetext{
${ }^{4}$ This is not to say that the wages in both countries do not change. In fact, to reach a viable equilibrium, both countries should witness identical percentage declines in their absolute wage rates.

${ }^{5}$ To avoid cluttering we did not portray different curves for the $A(z) \tau$ schedule in Figure 2. In line with the argumentation in the text, the (b) case $A(z) \tau$ schedule should have been drawn flatter than the (a) case $A(z) \tau$ schedule.

${ }^{6}$ As required to restore the balanced trade equilibrium. This can be most easily seen by taking the total derivative of (14), which yields $w a(\widetilde{z}) \widetilde{z} \widetilde{\tilde{z}}+N^{*} \tau^{*} a\left(\widetilde{z}^{*}\right) \widetilde{z}^{*} \widetilde{\widetilde{z}}^{*}=\left[\int_{\tilde{z}}^{u} a(s) d s\right] \hat{\tau}$.
} 
industries to Home. The direct consequence of the larger range of imported goods $\left(\widetilde{z}^{*}\right.$ increases) is that the real income of foreign households goes up, while that of the home households does not change. Due to asymmetric demand complementarities the increase in real income is spent on foreign goods only rather than on imports from Home. Regardless which country reduces its tariffs, therefore, the ensuing real income gains are spent on foreign goods. This implies that the equilibrium effects on the endogenous variables will be highly similar as before. Due to lowering its tariffs, Foreign unambiguously increases the number of goods it imports ( $\widetilde{z}^{*}$ increases), while the effects on relative wages and the number of goods exported are ambiguous. Formally,

$$
\begin{gathered}
\frac{\widehat{\widetilde{z}}^{*}}{\widehat{\tau}^{*}}=-\frac{1}{D}\left[\zeta(\widetilde{z}) N^{*} \tau^{*} \int_{0}^{\tilde{z}^{*}} w a(s) d s+N \tau w a(\widetilde{z}) \widetilde{z}\right]<0 \\
\frac{\widehat{w}}{\widehat{\tau}^{*}}=-\frac{\zeta(\widetilde{z})}{D}\left[N^{*} \tau^{*} w a\left(\widetilde{z}^{*}\right) \widetilde{z}^{*}-\zeta\left(\widetilde{z}^{*}\right) N^{*} \tau^{*} \int_{0}^{\widetilde{z}^{*}} w a(s) d s\right] \gtrless 0 \\
\frac{\widehat{\widetilde{z}}}{\widehat{\tau}^{*}}=\frac{1}{D}\left[N^{*} \tau^{*} w a\left(\widetilde{z}^{*}\right) \widetilde{z}^{*}-\zeta\left(\widetilde{z}^{*}\right) N^{*} \tau^{*} \int_{0}^{\widetilde{z}^{*}} w a(s) d s\right] \gtrless 0 .
\end{gathered}
$$

Note that also the condition that settles the effect on $w$ and $\tilde{z}$ is similar in nature to the one derived before: if $\zeta\left(\widetilde{z}^{*}\right)>(<) w a\left(\widetilde{z}^{*}\right) \widetilde{z}^{*} / \int_{0}^{\widetilde{z}^{*}} w a(s) d s$, then Foreign's factor terms of trade improve (deteriorate) and $\widetilde{z}$ goes up (down). ${ }^{7} \quad$ As before, and in contrast with the DFS model, a unilateral tariff reduction does not necessarily improve a country's terms of trade.

The analysis so far can also be used to discuss the consequences of multilateral tariff reductions, that is when $d \tau / \tau=d \tau^{*} / \tau^{*}<0$. This is useful since tariff reductions typically

\footnotetext{
${ }^{7}$ The effects can also be easily illustrated in a graph like Figure 1, provided that we express the trade balance condition as a function of $\widetilde{z}^{*}$ only. Then, a lower $\tau^{*}$ implies that both the $A(z) / \tau^{*}$ and the trade balance condition shift to the right, which leads to an unambiguous increase of $\widetilde{z}^{*}$. The effects on $w$ and $\widetilde{z}$ would then depend on the relative shift of both curves, just as it was the case when Home reduced its tariffs.
} 
are the outcome of bilateral or multilateral negotiations between countries based on reciprocity. The results for multilateral tariff reductions are obtained by adding the effects of the unilateral reductions of $\tau$ and $\tau^{*}$. From the previous discussion it follows straightforwardly that lower world tariffs unambiguously reduce the range of nontraded goods, that is $d \widetilde{z}<0$ and $d \widetilde{z}^{*}>0$. In terms of Figure 2, a small uniform decrease in both tariff rates shifts the schedule $A(z) / \tau^{*}$ to the right and the schedule $A(z) \tau$ and the trade balance condition (16) to the left. The effect on the factor terms of trade is still ambiguous. A uniform tariff decrease has zero effect on relative wages only if the relative decline in labor due to the loss of competitiveness exactly matches the relative decline in labor demand. In contrast, DFS show that a uniform reduction in world tariff rates reduces the range of nontraded goods but has no effect on the relative wage rate when the income share in world income is equal for each country. Multilateral tariff reductions lower the relative price in each country exactly in proportion to the tariff.

Welfare effects of trade liberalization

The welfare effects of tariff reductions - unilateral and multilateral - can be decomposed into a factor terms of trade effect and a tariff revenue effect. Total differentiation of (4) and (5) yields, for a home household

$$
a^{*}(u) d u=\left[\int_{\widetilde{z}}^{u} a^{*}(s) d s\right] \hat{w}-(\tau-1) a^{*}(\widetilde{z}) \widetilde{\widetilde{z}}
$$

and, for a foreign household

$$
a^{*}\left(u^{*}\right) d u^{*}=-\left[w \int_{0}^{\widetilde{z}^{*}} a(s) d s\right] \widehat{w}+\left(\tau^{*}-1\right) w a\left(\widetilde{z}^{*}\right) \widetilde{z}^{*} \widehat{\widetilde{z}}^{*}
$$

The first terms on the right hand side of both equations represent the factor terms of trade effect weighted by the country's value of imports. The second term reflects the change in tariff revenues on account of lower tariffs due to the change in the quantity traded, holding tariff rates constant. It can also be interpreted as the change in deadweight loss caused by the change in import volume. Since we started from a tariff distorted equilibrium there is also a price effect of lower tariffs on the tariff revenues, holding quantity constant. This 
price effect, however, drops out since with homogeneous population, the gains of lower prices for imported goods is exactly matched by lower rebated tariff revenues.

Applying the equilibrium effects of unilateral or multilateral tariff reductions, then shows that the total welfare effects are ambiguous and critically depend on the induced change of $w$. To see this, consider a unilateral tariff reduction by Home. Then, if $\widehat{w}<0$, no clear conclusions can be drawn for Home, since the total welfare effect depends on the relative magnitude of the terms of trade effect and the tariff revenue effect. ${ }^{8}$ Foreign gains though. Note that equations (25) and (26) suggest that the lower Home's initial imports, the more likely it is that also Home gains from lower tariffs. This result is in accordance with DFS. However, results differ sharply from DFS if $\widehat{w}>0$. Home's terms of trade improve and allows home households to shift expenditure away from home goods towards higher-indexed goods. This effect is reinforced by higher tariff revenues, increasing the consumption basket of home households unambiguously: $d u>0$. Foreign's welfare declines though: not only does Foreign witness a deterioration in its factor terms of trade but also less tariff revenues accrue. In this case Foreign loses industries at the higher end of the spectrum but gains industries at the lower end. The difference in results is due to nonhomotheticity.

This analysis can be applied to both unilateral and multilateral trade liberalization. The general inference is that a country gains from a unilateral tariff reduction when its factor terms of trade improves, irrespective of which country lowers the tariffs. When the terms of trade deteriorate, a unilateral tariff reduction is bad for a country, unless it is the incipient country, that is: when it has lowered the tariff itself. Then, a worsened factor terms of trade might be compensated by the unambiguous increase in the range of imports. For multilateral tariff reductions the results for the incipient country obviously hold for both countries.

The importance of the factor terms of trade for the welfare effects of trade policy is in line with the standard literature on the welfare effects of trade policy. The point in case is, however, that in our analysis a tariff reduction does not necessarily lead to a terms

\footnotetext{
${ }^{8}$ Of course, this ambiguity is absent when starting from a free-trade equilibrium. In this case welfare changes are determined completely by the changes in factor terms of trade.
} 
of trade deterioration for the incipient country. Hence, the general notion that unilateral trade liberalization is good for the exporting partner country does not hold in our analysis.

We finally note that in our analysis also the pattern of product cycles emerges: new industries appear in Foreign, and some older foreign industries are taken over by Home. Such product cycles do not appear in DFS since the range of products is fixed. In our model, the upper range of products is open. In this context, it is interesting to note that successive unilateral trade liberalizations by Foreign generate product cycle phenomena, similar to those discussed by Vernon (1966) and Linder (1961). Unilateral reduction in foreign tariffs may lead to a fall in Home's terms of trade and industries at the lower end in Foreign move to Home over time. Relatively cheaper home commodities allow foreign households to shift expenditure away from home goods to higher-indexed foreign goods thereby providing the economic climate for new industries to be developed in Foreign.

\section{Heterogeneous Population}

In this section we consider differences in income distribution, that is we assume that the distributions $F(h)$ and $F^{*}\left(h^{*}\right)$ are nondegenerated. This is particularly interesting when income of the households with low skill levels is so low in equilibrium that they are not able to consume higher-indexed goods produced in Foreign. For the sake of concreteness, we therefore assume that there are two types of households in both countries, those with low skill levels $\left(h_{L}, h_{L}^{*}\right)$ and those with high skill levels $\left(h_{H}, h_{H}^{*}\right)$, which are moreover equal in number. Hence, in Home there are $N / 2$ households that do not import, so that $u_{L}<\tilde{z}$, while in Foreign there are $N^{*} / 2$ households who only import, that is: for those households $u_{L}^{*}<\tilde{z}^{*}$.

For the analysis of trade liberalization this implies that the effects now become crucially dependent on how the tariff revenues are distributed, since also households that do not import might then be affected by trade policy. Many tariff revenue distribution schemes are possible. In the remainder of the analysis we consider three of them: (1) tariff revenues are rebated to households proportional to their imports (proportionality scheme); (2) tariff rev- 
enues are distributed evenly over households, regardless of individual consumption patterns (per capita scheme); and (3) all tariff revenues are rebated to the poor in society (pro poor scheme). As the distribution schemes may differ between countries, this delineates a total of 9 different cases. Each case has its own particular budget constraints and concomitant trade balance equation, which are given in the appendix. For here it suffices to say that since Foreign comprises households that spend their marginal income on home goods, the trade balance condition also depends on $w$. In terms of Figure 1: then the TB curve is upward sloping for all values of $w$.

For analytical convenience, we put $\tau=\tau^{*}=1$ in this section, as if initially both countries do not levy tariffs. The appendix gives the analytical results for positive tariffs. The subscripted short-hand notations we use in the appendix to distinguish between the different cases simplify considerably. These are given in Table 1, which for the sake of completeness also includes the values for the homogenous population case.

For a unilateral tariff reduction in Home, we then derive

$$
\frac{\widehat{\widetilde{z}}}{\widehat{\tau}}=\frac{1}{D_{i i^{*}}}\left[\Gamma_{i} \zeta\left(\widetilde{z}^{*}\right) N \int_{\widetilde{z}}^{u_{H}} a^{*}(s) d s+\frac{1}{2} N^{*} w a\left(\widetilde{z}^{*}\right) \widetilde{z}^{*}+\frac{1}{2} \zeta\left(\widetilde{z}^{*}\right) N^{*} h_{L}^{*}\right]>0
$$

with $D_{i i^{*}}>0$ for all $i, i^{*}$. Irrespective of the particular tariff distribution scheme, therefore, unilateral trade liberalization by Home always leads to a loss of home industries. Due to the dependency of the balanced trade condition on $w$, we note that compared to the case of homogenous population, an additional term appears in (27). This reflects the fact that poor households in Foreign only buy low-indexed home goods. Consequently, everything else the same, Home must free more labor to accommodate the additional demand by Foreign poor households for their goods. Likewise, if all tariff revenues in Home are rebated to the poor population (pro poor scheme), the loss of home industries is mitigated since the additional income is spent on domestic products only $\left(\Gamma_{i}=0\right)$.

The ambiguity on $\hat{w}$ and $\widehat{\widetilde{z}}^{*}$ from the homogeneous case carries over to the heterogenous case: 


$$
\begin{aligned}
\frac{\widehat{w}}{\widehat{\tau}} & =\frac{\zeta\left(\widetilde{z}^{*}\right)}{D_{i i^{*}}}\left[\frac{1}{2} N w a(\widetilde{z}) \widetilde{z}-\Gamma_{i} \zeta(\widetilde{z}) N \int_{\widetilde{z}}^{u_{H}} a^{*}(s) d s\right] \gtrless 0 \\
\frac{\widehat{\widetilde{z}}^{*}}{\widehat{\tau}} & =-\frac{1}{D_{i i^{*}}}\left[\frac{1}{2} N w a(\widetilde{z}) \widetilde{z}-\Gamma_{i} \zeta(\widetilde{z}) N \int_{\widetilde{z}}^{u_{H}} a^{*}(s) d s\right] \gtrless 0 .
\end{aligned}
$$

The condition that settles whether or not Home's factor terms of trade increases upon trade liberalization is similar as before, but its strictness depends on the case considered. Formally: $\hat{w} / \hat{\tau} \gtreqless 0$ if $w a(\widetilde{z}) \widetilde{z} / \int_{\widetilde{z}}^{u_{H}} a^{*}(s) d s \gtreqless 2 \Gamma_{i} \zeta(\widetilde{z})$. Everything else the same, it is more likely that Home's factor terms of trade improve in the proportionality case than in the per capita case, whereas Home's terms of trade will always deteriorate when tariff revenues are only rebated to the poor. If the latter is the case, then also Home's export range increases unambiguously when home tariffs go down $\left(\Gamma_{i}=0\right)$. Since poor households in Home only buy domestic goods, the income the rich households in Home 'save' by not longer buying domestic goods is never completely spent on foreign goods and the relative demand decline for home labor always falls short of the negative supply effect due to loss in competitiveness.

Unilateral trade liberalization by Foreign leads to:

$$
\frac{\widehat{\widetilde{z}}^{*}}{\widehat{\tau}^{*}}=-\frac{1}{D_{i i^{*}}}\left[\Gamma_{i^{*}}^{*} \zeta(\widetilde{z}) N^{*}+\frac{1}{2} N w a(\widetilde{z}) \widetilde{z}+\frac{1}{2} \zeta(\widetilde{z}) N^{*} h_{L}^{*}\right]<0 .
$$

The sign of (30) is as before, but the extent to which Foreign loses industries to Home varies across cases. The effects on $w$ and $\widehat{\widetilde{z}}$ are:

$$
\begin{gathered}
\frac{\widehat{\widetilde{z}}}{\widehat{\tau}^{*}}=\frac{1}{D_{i i^{*}}}\left[\frac{1}{2} N^{*} w a\left(\widetilde{z}^{*}\right) \widetilde{z}^{*}-\Gamma_{i^{*}}^{*} \zeta\left(\widetilde{z}^{*}\right) N^{*}\right] \gtrless 0 \\
\frac{\widehat{w}}{\widehat{\tau}^{*}}=-\frac{\zeta(\widetilde{z})}{D_{i i^{*}}}\left[\frac{1}{2} N^{*} \tau^{*} w a\left(\widetilde{z}^{*}\right) \widetilde{z}^{*}-\Gamma_{i^{*}}^{*} \zeta\left(\widetilde{z}^{*}\right) N^{*}\right] \gtrless 0 .
\end{gathered}
$$

Again the similarities with the homogeneous population case are apparent, be it that now also the way tariff revenues are distributed matter: Home's factor terms of trade increases upon trade liberalization if $w a(\widetilde{z}) \widetilde{z}>2 \Gamma_{i^{*}}^{*} \zeta(\widetilde{z})$.

Our assumptions on income distributions and the allocation of tariff revenues now warrant a discussion of the induced welfare changes for each type of households in both countries. Consequently, (25) and (26) become: 


$$
\begin{aligned}
a^{*}\left(u_{H}\right) d u_{H} & =\left[\int_{\widetilde{z}}^{u_{H}} a^{*}(s) d s\right] \hat{w}-\gamma_{i}\left[\int_{\tilde{z}}^{u_{H}} a^{*}(s) d s\right] \hat{\tau} \\
w a\left(u_{L}\right) d u_{L} & =\gamma_{i}\left[\int_{\widetilde{z}}^{u_{H}} a^{*}(s) d s\right] \hat{\tau} \\
a^{*}\left(u_{H}^{*}\right) d u_{H}^{*} & =-\left[\int_{0}^{\tilde{z}^{*}} w a(s) d s\right] \hat{w}-\gamma_{i^{*}} \hat{\tau}^{*} \\
w a\left(u_{L}^{*}\right) d u_{L}^{*} & =-\left[\int_{0}^{u_{L}^{*}} w a(s) d s\right] \hat{w}+\gamma_{i^{*}} \hat{\tau}^{*}
\end{aligned}
$$

with $\gamma_{i}=\{0,1 / 2,1\}$ and $\gamma_{i^{*}}^{*}=\left\{0,\left[\int_{0}^{\tilde{z}^{*}} w a(s) d s-\int_{0}^{u_{L}^{*}} w a(s) d s\right] / 2, \int_{0}^{\widetilde{z}^{*}} w a(s) d s\right\}$ evaluated at $\tau=\tau^{*}=1$.

As before, the welfare effects of trade liberalization depend on the effect on a country's terms of trade, except for the poor in Home. Since the poor households in Home do not import, they are insulated from the factor terms of trade effect of policy changes. For poor households in Foreign, as well as for rich households, the terms of trade changes work in the same direction as in the homogeneous population case. Equations (33)-(36) also underscore the importance of the particular tariff revenue redistribution scheme. When tariff revenues are redistributed from rich to poor households, this provides a channel by which tariff reductions work against the poor in society, since it lowers the income they get via tariff rebates. ${ }^{9}$

This leads to the following conclusions. A terms of trade improvement is always good for the rich in society, irrespective of which country liberalizes trade, but also irrespective of the tariff revenue redistribution scheme. In fact, redistributing tariff revenues from rich to poor households is welfare improving for the rich. Such redistribution might even allow rich households to gain when the terms of trade deteriorate. For the poor, the virtuous effect of a more favorable factor terms of trade depends very much on (a) which country

${ }^{9}$ For positive tariffs, equations (33)-(36) also incorporate a term with $\widehat{\widetilde{z}}$ and $\widehat{\widetilde{z}}^{*}$ that reflects the quantity effect of the tariff revenue change (as opposed to the price effect that $\hat{\tau}$ and $\hat{\tau}^{*}$ constitute). The way the quantity effect works through on the welfare of poor and rich housholds is obviously the same as that for the price effect. 
liberalizes trade, and (b) how the tariff revenues are redistributed across households. When the latter involves a redistribution from rich to poor households, we see that the poor in the incipient country are always worse off compared to the situation when tariff revenues are distributed proportionally. For the welfare effects of multilateral tariff reductions, this implies that these are less positive for poor households, and might even become negative, when a government pursues an income redistribution policy in favor of the poor. When preferences are nonhomothetic, trade liberalization reduces the efficacy of pro poor income redistribution policies.

Like in the homogeneous population case, we note finally that both unilateral and multilateral tariff reductions lead to the emergence of product cycles if $d w<0$. In contrast to the homogeneous case, however, the birth of new industries is primarily driven by the higher purchasing power of rich foreign households. Their consumption basket increases the more when trade is liberalized, and the larger is the share of tariff revenues allocated to the poor foreign households. This leads to the interesting observation that the more pro poor the income redistribution policy, the more effective trade liberalization is in spurring the birth of new industries (innovation). Since we have seen above that such redistribution policies reduce the welfare gains of trade liberalization for poor households, when deciding on the particular redistribution policy, the government faces the dilemma of choosing between the (potential) benefits of innovation for all in the future and the current welfare gains of the poor now.

\section{Conclusion}

Traditionally, international economists make the simplifying assumption of homothetic preferences when analyzing the effects of trade policy. This assumption implies that all goods have the same unitary income elasticities and that poor and rich households consume all available goods in the same proportion. Homotheticity has certainly its justification when analyzing trade policy questions between countries characterized by similar per capita income. When considering issues of trade and development between rich and poor countries 
the assumption of a negligible income effect seems less appropriate. The lower is the income level of a country, the more likely it is that its poorest households are isolated from the broader economy. Effects of lower trade taxes might then not pass through to those households and the welfare effects of trade liberalization are then more a matter of income growth than of (relative) price declines. Standard trade models based on homothetic preferences are not suitable to address these issues, even though they seem highly relevant in assessing the consequences of better market access for developing countries.

In this paper we therefore abandon the assumption of homothetic preferences and look at the consequences of trade liberalization when preferences are non-homothetic. To this end we have used the analytical framework of Matsuyama (2000) and have extended it to include trade taxes. The production side is characterized by a continuum of goods, where goods are ordered in terms of comparative advantage and desirability in consumption. The demand side entails nonhomothetic preferences, which are modeled by assuming that consumers are satiated after the consumption of one unit. As a consequence, when household income increases, this takes the form of adding higher-indexed goods to the consumption basket and not of increased consumption of the goods already consumed. This implies that poor households in society have different consumption baskets than rich households, just like poor and rich households in developing countries have different consumption baskets than their counterparts in developed countries. It also implies that the way governments distribute tariff revenues among poor and rich households becomes important in gauging the effects of trade liberalization. To apply the model to trade liberalization between developed and developing countries, we assume that the world consists of a poor, developing country (Home) and a rich, developed country (Foreign). The poor country has a comparative advantage in the production of the lower range of goods and specializes in goods with low income elasticity of demand. The rich country on the other hand, has a comparative advantage in the production of the higher-spectrum of goods and hence is specialized in the commodities with high income elasticity of demand.

Our paper shows that in the presence of nonhomothetic preferences the effects of trade liberalization are neither standard, nor straightforward. In particular we have looked at 
the consequences of unilateral and multilateral reductions of tariffs for (i) the ranges of goods produced and traded by each country, (ii) the terms of trade, and (iii) welfare, all under different schemes of tariff redistribution and under different assumptions regarding the homogeneity of households. The main results can be summarized as follows.

First, when a country reduces its tariffs, it unambiguously leads to a loss of domestic industries to the other country. However, in contrast to the standard literature, trade liberalization does not necessarily deteriorate the terms of trade of the incipient country. This depends on the extent by which the country loses goods due to diminished competitiveness, compared to what is required to get trade balance equilibrium.

Second, the terms of trade effect is highly important in determining the welfare effects of trade liberalization. The general outcome is that a country gains from a tariff reduction, regardless which country lowers the tariffs, whenever its terms of trade improves. When the terms of trade deteriorate, a unilateral tariff reduction is always bad for a country, unless it is the incipient country. Then, a worsened factor terms of trade might be compensated by the unambiguous increase in the range of imports.

Third, when households are heterogeneous in the sense that some are poorer than others, the welfare effects for households of trade liberalization highly depend on the particular tariff distribution scheme a government applies. When tariff revenues are redistributed from rich to poor households, an additional channel occurs by which tariff reductions work against the poor in society, since it lowers the income they get via tariff rebates. We are then able to show that a terms of trade improvement is always good for the rich in society, but not necessarily for the poor. In fact, the more in favor of the poor the tariff redistribution scheme is, the better trade liberalization works out for the rich and the worse it becomes for the poor. This sheds new light on the efficacy of income redistribution policies in the wake of ongoing trade liberalizations.

Fourth, our framework provides a link with the literature on product cycles, since due to further economic integration new industries appear in the rich country, while some of its older industries move to the developing country. As we show, when preferences are nonhomothetic the birth of new industries is primarily driven by the higher purchasing 
power of rich households in the rich country. As a consequence, the more pro poor the income redistribution policy of a government is, the more effective trade liberalization is in spurring the birth of new industries.

\section{APPENDIX}

The different cases we consider in the main text are delineated by the particular way the tariff revenues are rebated and the assumptions we make regarding the distribution of households in each country. For an equal division of the total number of households over poor and rich households and given that we assume that in equilibrium poor households in each country do not buy the higher indexed goods from Foreign, the following expressions for total tariff revenues are due:

$$
\begin{aligned}
T & =\frac{N}{2}(\tau-1) \int_{\widetilde{z}}^{u_{H}} a^{*}(s) d s \\
T^{*} & =\frac{N^{*}}{2}\left(\tau^{*}-1\right)\left[\int_{0}^{\widetilde{z}^{*}} w a(s) d s+\int_{0}^{u_{L}^{*}} w a(s) d s\right]
\end{aligned}
$$

For homogeneous population all tariff distribution schemes yield tariff rebates of $(\tau-$ 1) $\int_{\tilde{z}}^{u} a^{*}(s) d s$ and $\left(\tau^{*}-1\right) \int_{0}^{\tilde{z}^{*}} w a(s) d s$ per home and foreign household, respectively. For heterogenous population, the different tariff distribution schemes imply the following tariff rebates per type of household:

$\begin{array}{lllll} & \mathbf{T R}_{L} & \mathbf{T R}_{H} & \mathbf{T R}_{L}^{*} & \mathbf{T R}_{H}^{*} \\ \text { proportionality } & 0 & 2 T / N & \left(\tau^{*}-1\right) \int_{0}^{u_{L}^{*}} w a(s) d s & \left(\tau^{*}-1\right) \int_{0}^{\tilde{z}^{*}} w a(s) d s \\ \text { per capita } & T / N & T / N & T^{*} / N^{*} & T^{*} / N^{*} \\ \text { pro poor } & 2 T / N & 0 & 2 T^{*} / N^{*} & 0\end{array}$

The budget constraints for homogenous population are given by (17) and (18) in the main text. For heterogenous households, the case specific budget constraints become, for households in Home:

$$
\begin{aligned}
\int_{0}^{\tilde{z}} w a(s) d s+A_{j} \int_{\widetilde{z}}^{u_{H}} a^{*}(s) d s & =w h_{H} \\
\int_{0}^{u_{L}} w a(s) d s & =w h_{L}+B_{j}\left[w h_{H}-\int_{0}^{\tilde{z}} w a(s) d s\right]
\end{aligned}
$$


where $A_{j}=\{1,(\tau+1) / 2, \tau\}$ and $B_{j}=\{0,(\tau-1) /(\tau+1),(\tau-1) / \tau\}$ for $j=$ proportionality, per capita, pro poor\}. For households in Foreign we get:

$$
\begin{aligned}
A_{j^{*}}^{*} \int_{0}^{\tilde{z}^{*}} w a(s) d s+\int_{\tilde{z}^{*}}^{u_{H}^{*}} a^{*}(s) d s & =h_{H}^{*}+C_{j^{*}}^{*} \int_{0}^{u_{L}^{*}} w a(s) d s \\
D_{j^{*}}^{*} \int_{0}^{u_{L}^{*}} w a(s) d s & =h_{L}^{*}+B_{j^{*}}^{*} \int_{0}^{\tilde{z}^{*}} w a(s) d s .
\end{aligned}
$$

where $A_{j^{*}}^{*}=\left\{1,\left(\tau^{*}+1\right) / 2, \tau^{*}\right\}, B_{j^{*}}^{*}=\left\{0,\left(\tau^{*}-1\right) / 2, \tau^{*}-1\right\}, C_{j^{*}}^{*}=\left\{0,\left(\tau^{*}-1\right) / 2,0\right\}$, and $D_{j^{*}}^{*}=\left\{1,\left(\tau^{*}+1\right) / 2,1\right\}$.

The balanced trade condition for heterogenous households becomes, instead of (14): $\frac{N^{*} \tau^{*}}{2}\left[\int_{0}^{u_{L}^{*}} w a(s) d\right.$ $\frac{N \tau}{2} \int_{\tilde{z}}^{u_{H}} a^{*}(s) d s$. In combination with the case specific budget constraints, all balanced trade conditions can be written as:

$$
N^{*} \tau^{*}\left[\Phi_{i^{*}}^{*} \int_{0}^{\widetilde{z}^{*}} w a(s) d s-\Theta_{i^{*}}^{*} h_{L}^{*}\right]=N \tau \Phi_{i}\left[w h_{H}-\int_{0}^{\widetilde{z}} w a(s) d s\right]
$$

where:

$$
\begin{aligned}
& \Phi_{i}=\left\{1,1 / 2, \frac{1}{\tau+1}, \frac{1}{2 \tau}\right\}, \\
& \Phi_{i^{*}}^{*}=\left\{1,1 / 2, \frac{\tau^{*}}{\tau^{*}+1}, \frac{1}{2 \tau^{*}}\right\}, \\
& \Theta_{i^{*}}^{*}=\left\{0,1 / 2, \frac{1}{\tau^{*}+1}, 1 / 2\right\},
\end{aligned}
$$

for $i=\{$ proportionality, per capita, pro poor . Total differentiation of this equation and the two relative efficiency equations (2) and (3) yields, in matrix form and by using the budget constraints above to substitute for $\left[w h_{H}-\int_{0}^{\widetilde{z}} w a(s) d s\right]$ :

$$
\begin{aligned}
{\left[\begin{array}{ccc}
1 & \zeta(\widetilde{z}) & 0 \\
-1 & 0 & -\zeta\left(\widetilde{z}^{*}\right) \\
-\Theta_{i^{*}}^{*} N^{*} \tau^{*} h_{L}^{*} & \Phi_{i} N \tau w a(\widetilde{z}) \widetilde{z} & \Phi_{i^{*}}^{*} N^{*} \tau^{*} w a\left(\widetilde{z}^{*}\right) \widetilde{z}^{*}
\end{array}\right]\left[\begin{array}{c}
\hat{w} \\
\widehat{\widetilde{z}} \\
\widehat{\widetilde{z}}^{*}
\end{array}\right]=} \\
{\left[\begin{array}{cc}
1 & 0 \\
0 & 1 \\
\Gamma_{i} N \tau \int_{\widetilde{z}}^{u_{H}} a^{*}(s) d s & -\Gamma_{i^{*}}^{*} N^{*} \tau^{*}
\end{array}\right]\left[\begin{array}{c}
\hat{\tau} \\
\hat{\tau}^{*}
\end{array}\right] }
\end{aligned}
$$

with: 


$$
\begin{aligned}
\Gamma_{i}= & \left\{1,1 / 2,1 / 2 \frac{1}{\tau+1}, 0\right\}, \text { and } \\
\Gamma_{i^{*}}^{*}= & \left\{\int_{0}^{\tilde{z}^{*}} w a(s) d s,\left[h_{L}^{*}+\int_{0}^{\tilde{z}^{*}} w a(s) d s\right] / 2,\left[h_{L}^{*}+\tau^{*}\left(2+\tau^{*}\right) \int_{0}^{\tilde{z}^{*}} w a(s) d s\right] /\right. \\
& \left.\left(\tau^{*}+1\right)^{2},\left[h_{L}^{*}+2 \tau^{*} \int_{0}^{\widetilde{z}^{*}} w a(s) d s\right] / 2\right\}
\end{aligned}
$$

for $i=\{$ homogeneous, proportionality, per capita, pro poor $\}$. Taking the inverse gives,

$$
\left[\begin{array}{c}
\hat{w} \\
\widehat{\widetilde{z}} \\
\widehat{\widetilde{z}}^{*}
\end{array}\right]=\frac{1}{D_{i i^{*}}}\left[\begin{array}{ccc}
\Phi_{i} \zeta\left(\widetilde{z}^{*}\right) N \tau w a(\widetilde{z}) \widetilde{z} & -\zeta(\widetilde{z}) \Phi_{i^{*}}^{*} N^{*} \tau^{*} w a\left(\widetilde{z}^{*}\right) \widetilde{z}^{*} & -\zeta(\widetilde{z}) \zeta\left(\widetilde{z}^{*}\right) \\
\Phi_{i^{*}}^{*} N^{*} \tau^{*} w a\left(\widetilde{z}^{*}\right) \widetilde{z}^{*} & \Phi_{i^{*}}^{*} N^{*} \tau^{*} w a\left(\widetilde{z}^{*}\right) \widetilde{z}^{*} & \zeta\left(\widetilde{z}^{*}\right) \\
+\Theta_{i^{*}}^{*} \zeta\left(\widetilde{z}^{*}\right) N^{*} \tau^{*} h_{L}^{*} & -\Phi_{i} N \tau w a(\widetilde{z}) \widetilde{z} & \\
-\Phi_{i} N \tau w a(\widetilde{z}) \widetilde{z} & -\Theta_{i^{*}}^{*} \zeta(\widetilde{z}) N^{*} \tau^{*} h_{L}^{*} & \zeta(\widetilde{z}) \\
1 & 0 \\
0 & 1 \\
\Gamma_{i} N \tau \int_{\widetilde{z}}^{u_{H}} a^{*}(s) d s & -\Gamma_{i^{*}}^{*} N^{*} \tau^{*}
\end{array}\right]\left[\begin{array}{c}
\hat{\tau} \\
\hat{\tau}^{*}
\end{array}\right]
$$

with $D_{i i^{*}}=\Phi_{i} \zeta\left(\widetilde{z}^{*}\right) N \tau w a(\widetilde{z}) \widetilde{z}+\Phi_{i^{*}}^{*} \zeta(\widetilde{z}) N^{*} \tau^{*} w a\left(\widetilde{z}^{*}\right) \widetilde{z}^{*}+\Theta_{i^{*}}^{*} \zeta(\widetilde{z}) \zeta\left(\widetilde{z}^{*}\right) N^{*} \tau^{*} h_{L}^{*}>0, \forall i, i^{*}$. The expressions (27)-(29) and (30)-(32) in the main text then readily follow.

The welfare effects of trade liberalization are obtained by totally differentiating the case specific budget constraints. This yields, for home households,

$$
\begin{aligned}
& a^{*}\left(u_{H}\right) d u_{H}=\alpha_{i}^{H}\left[\int_{\widetilde{z}}^{u_{H}} a^{*}(s) d s\right] \hat{w}-\beta_{i}^{H}\left[(\tau-1) a^{*}(\widetilde{z}) \widetilde{z}\right] \widehat{\widetilde{z}}-\gamma_{i}\left[\int_{\widetilde{z}}^{u_{H}} a^{*}(s) d s\right] \hat{\tau} \\
& w a\left(u_{L}\right) d u_{L}=\alpha_{i}^{L}\left[\int_{\widetilde{z}}^{u_{L}} a^{*}(s) d s\right] \hat{w}-\beta_{i}^{L}\left[(\tau-1) a^{*}(\widetilde{z}) \widetilde{z}\right] \widehat{\widetilde{z}}+\gamma_{i}\left[\int_{\widetilde{z}}^{u_{H}} a^{*}(s) d s\right] \hat{\tau}
\end{aligned}
$$

with:

$$
\begin{aligned}
& \alpha_{i}^{H}=\{1,1,1,1\}, \\
& \alpha_{i}^{L}=\{1,0,0,0\}, \\
& \beta_{i}^{H}=\{1,1,1 /(\tau+1), 0\}, \\
& \beta_{i}^{L}=\{1,0, \tau /(\tau+1), 1\}, \\
& \gamma_{i}=\{0,0, \tau /(\tau+1), 1\} .
\end{aligned}
$$


For foreign households we obtain:

$$
\begin{aligned}
& a^{*}\left(u_{H}^{*}\right) d u_{H}^{*}=-\alpha_{i^{*}}^{H}\left[\int_{0}^{\widetilde{z}^{*}} w a(s) d s\right] \hat{w}+\beta_{i^{*}}^{H}\left[\left(\tau^{*}-1\right) w a\left(\widetilde{z}^{*}\right) \widetilde{z}^{*}\right] \widehat{\widetilde{z}}^{*}-\gamma_{i^{*}} \hat{\tau}^{*} \\
& w a\left(u_{L}^{*}\right) d u_{L}^{*}=-\alpha_{i^{*}}^{L} \hat{w}+\beta_{i^{*}}^{L}\left[\left(\tau^{*}-1\right) w a\left(\widetilde{z}^{*}\right) \widetilde{z}^{*}\right] \widehat{\widetilde{z}}^{*}+\gamma_{i^{*}} \hat{\tau}^{*}
\end{aligned}
$$

with:

$$
\begin{aligned}
\alpha_{i^{*}}^{H}= & \left\{1,1,2 \tau^{*} /\left(\tau^{*}+1\right), \tau^{*}\right\}, \\
\alpha_{i^{*}}^{L}= & \left\{\int_{0}^{\tilde{z}^{*}} w a(s) d s, \int_{0}^{u_{L}^{*}} w a(s) d s, \int_{0}^{u_{L}^{*}} w a(s) d s-\frac{\tau^{*}-1}{\tau^{*}+1} \int_{0}^{\tilde{z}^{*}} w a(s) d s,\right. \\
& \left.\frac{1}{2}\left(\tau^{*}+1\right) \int_{0}^{u_{L}^{*}} w a(s) d s-\frac{1}{2}\left(\tau^{*}-1\right) \int_{0}^{\widetilde{z}^{*}} w a(s) d s\right\} \\
\beta_{i^{*}}^{H}= & \left\{1,1, \tau^{*} /\left(\tau^{*}+1\right), 0\right\}, \\
\beta_{i^{*}}^{L}= & \left\{1,0,1 /\left(\tau^{*}+1\right), 1\right\}, \\
\gamma_{i^{*}}= & \left\{0,0, \tau^{*}\left[\int_{0}^{\widetilde{z}^{*}} w a(s) d s-\int_{0}^{u_{L}^{*}} w a(s) d s\right] /\left(\tau^{*}+1\right), \tau^{*} \int_{0}^{\widetilde{z}^{*}} w a(s) d s\right\} .
\end{aligned}
$$


Dornbusch, R., Fischer, S., Samuelson, P., 1977. Comparative Advantage, Trade, and Payments in a Ricardian Model with a Continuum of Goods. American Economic Review 67, 823-39.

Dosi, G., Pavitt, K., Soete, L., 1988. The Economics of Technical Change and International Trade. Brighton: Wheatsheaf.

Hunter, L.C., 1991. The Contribution of Nonhomothetic Preferences to Trade. Journal of International Economics 30, 345-58.

Hunter, L.C., Markusen, J.R., 1987. Per-Capita Income as a Determinant of Trade, in: Feenstra, R. (Ed.), Empirical Method for International Trade, Cambridge, Mass.: MIT Press.

Linder, S.B., 1961. An Essay on Trade and Transformation. Uppsala: Almqvist \& Wiksell.

Matsuyama, K., 2000. A Ricardian Model with a Continuum of Goods under Nonhomothetic Preferences: Demand Complementarities, Income Distribution, and NorthSouth Trade. Journal of Political Economy, 108, 1093-1120.

Murphy, K., Shleifer, A., Vishny, R., 1989. Income Distribution, Market Size, and Industrialization. Quarterly Journal of Economics, 104, 537-564.

Obstfeld, M., Rogoff, K., 1999. Foundations of International Macroeconomics, Cambridge, Mass.: MIT Press.

Vernon, R., 1966. International Investment and International Trade in the Product Cycle. Quarterly Journal of Economics , 80, 190-207.

Wilson, C., 1980. On the General Structure of Ricardian Models with a Continuum of Goods: Applications to Growth, Tariff Theory, and Technical Change. Econometrica, 48, 1675-1702. 
Table 1: Short-hand notations for $\tau=\tau^{*}=1$

$i, i^{*}$ Homogeneous Proportionality Per capita Pro poor

$\begin{array}{lllll}\Phi_{i} & 1 & 1 / 2 & 1 / 2 & 1 / 2 \\ \Phi_{i^{*}}^{*} & 1 & 1 / 2 & 1 / 2 & 1 / 2 \\ \Gamma_{i} & 1 & 1 / 2 & 1 / 4 & 0 \\ & & \frac{1}{2}\left[h_{L}^{*}+\ldots\right. & \frac{1}{4}\left[h_{L}^{*}+\ldots\right. & \frac{1}{2}\left[h_{L}^{*}+\ldots\right. \\ \Gamma_{i^{*}}^{*} & \int_{0}^{\tilde{z}^{*}} w a(s) d s & \left.\int_{0}^{\tilde{z}^{*}} w a(s) d s\right] & \left.\ldots 3 \int_{0}^{\tilde{z}^{*}} w a(s) d s\right] & \left.2 \int_{0}^{\tilde{z}^{*}} w a(s) d s\right] \\ & & 1 / 2 & 1 / 2 & 1 / 2\end{array}$




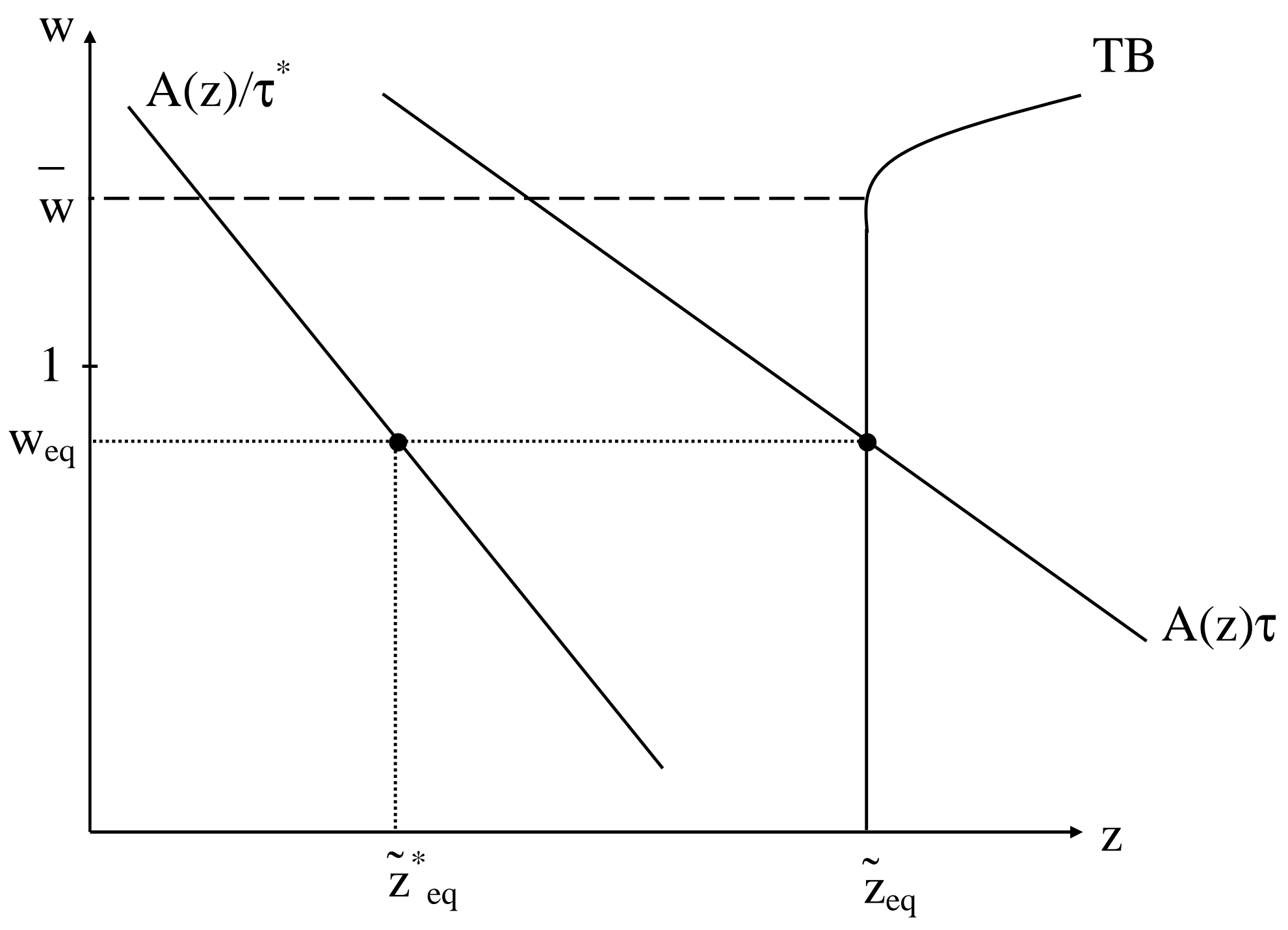

Figure 1.-Trade policy equilibrium: the case of homogeneous population. 


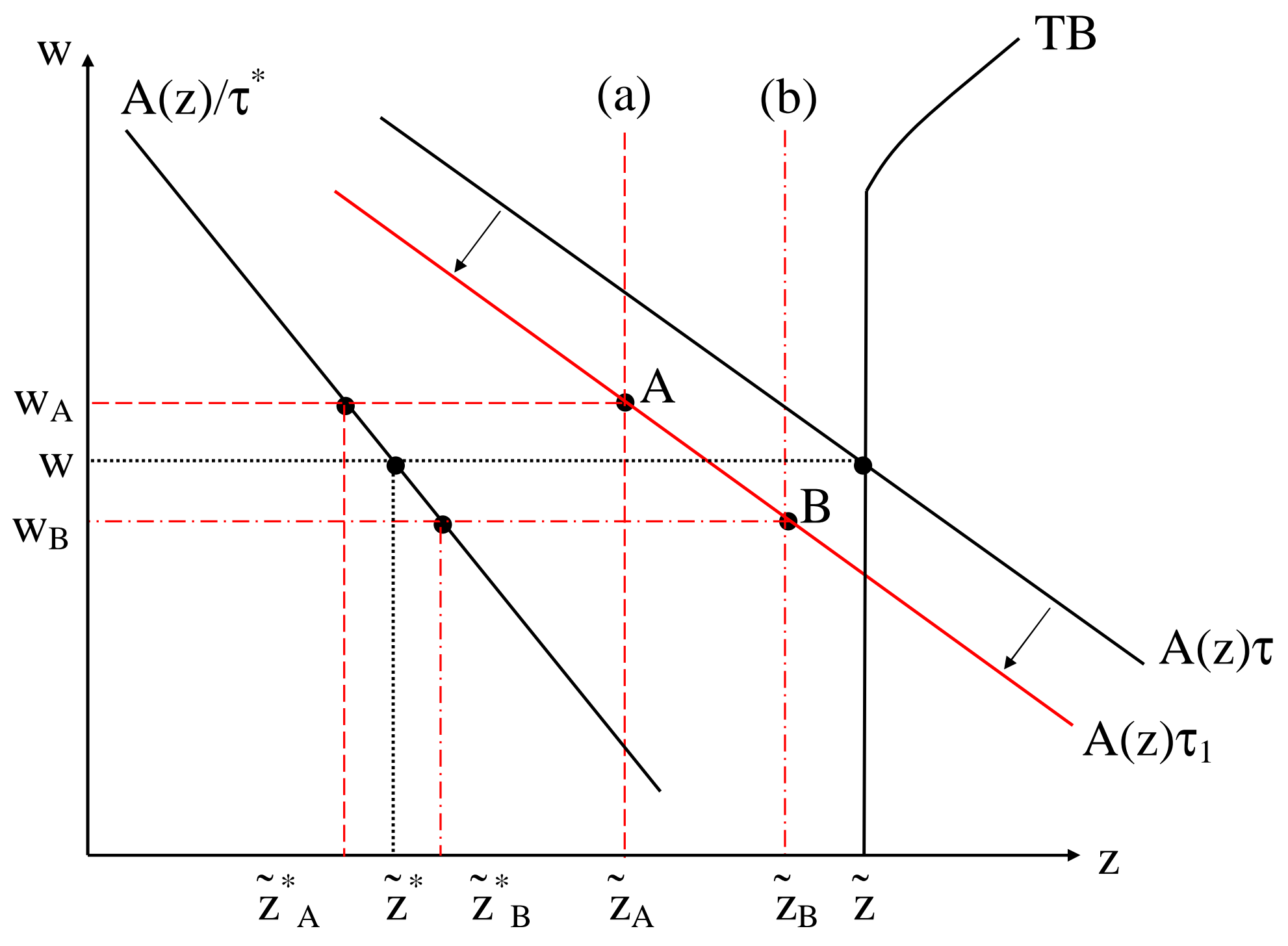

Figure 2.-Unilateral reduction in Home country's tariff for homogeneous population 